\title{
Mesenchymal stem cells for the treatment of tendon disorders
}

\author{
Lucia Machová Urdzíková ${ }^{1}$, Petr Lesný ${ }^{1,2}$, Eva Sykováa ${ }^{1,2}$, Pavla Jendelová ${ }^{1,2}$ \\ ${ }^{1}$ Institute of Experimental Medicine, Academy of Sciences of the Czech Republic, Prague, Czech Republic \\ ${ }^{2}$ Department of Neuroscience, Second Faculty of Medicine, Charles University, Prague, Czech Republic \\ Email: urdzik1@saske.sk
}

Received 22 May 2013; revised 28 June 2013; accepted 15 July 2013

Copyright (C) 2013 Lucia Machová Urdzíková et al. This is an open access article distributed under the Creative Commons Attribution License, which permits unrestricted use, distribution, and reproduction in any medium, provided the original work is properly cited.

\begin{abstract}
Tendon disorders are associated with increased morbidity and a reduction in the quality of life, especially in people of working age. Recently, a new approach, cell-based therapy, offers promising potential to treat tendon injuries. Mesenchymal stem cells are the most suitable candidates for such therapies due to their capacity to differentiate into cells of mesodermal origin, their paracrine properties and their potential use in autologous transplantation. This review summarizes experimental as well as clinical data focusing on the use of mesenchymal stem cells to treat tendinophaties.
\end{abstract}

Keywords: Tendinophaty; Tendinosis; Tendonitis; Models of Tendon Injuries; Mesenchymal Stem Cells; Rotator Cuff; Achilles Tendon; Tendon Rupture

\section{INTRODUCTION}

Tendon disorders represent a common diagnostic and therapeutic challenge, resulting in chronic and long lasting problems. The medical nomenclature uses terms such as "tendininis", "tendinophaty", "tenopathy", "tendonitis", "tendinosis" and "partial rupture" to describe exactly the same clinical entity, non-ruptured tendon injuries [1]. The term "tendinosis" refers to the degeneration of a tendon without any sign of an inflammatory response, while the term "tendonitis" is associated with an inflammatory reaction in the tendon. It has also been suggested that inflammation may occur early after an injury, but it is then superseded by a degenerative response [2]. Paratenonitis is an inflammation of the outer layers of a tendon, while paratenonitis with tendinosis is the degeneration of a tendon without any inflammatory reaction inside the tendon, but associated with paratenonitis. According to the duration of the symptoms, we can divide tendon disorders into three subcategories: 1$)$ acute ( $<2$ weeks); 2$)$ subchronic (4 - 6 weeks); and 3) chronic ( $>6$ weeks) [3].

The etiology of tendon disorders remains unclear. A combination of intrinsic and extrinsic factors is the most likely cause, but historically two main theories (mechanical and vascular) have been postulated. In the mechanical theory, tissue degeneration in tendons is associated with the overuse of the tendon tissue within the normal physiological range, which leads to tendon failure. The vascular theory claims that compromising the vascular supply leads to tendon tissue degeneration. Recently, a neural theory has been presented. The overuse of tendons could lead to excessive nerve stimulation and the activation of mast cells via neural endingsmast cell associations, leading to mast cell degranulation and the release of mediators such as substance P [4]. Systemic diseases (rheumatoid arthritis, sarcoidosis etc.), foreign bodies, metabolic and inherited diseases (Ehlers-Danlos syndrome, Marfan syndrome, homocystinuria etc.) or infectious diseases are only rarely the cause of tendinopathy. Ageing, endocrine factors and pharmacological agents can also affect the biomechanical properties of a tendon.

The healing response of a tendon is usually poor. In the acute phase, rapid haemorrhage and inflammation occur, followed by a proliferative phase with fibroblast production of new matrix. Several weeks after injury, the remodelling phase is underway; with the organization and maturation of collagen. Histologically, the signs of tendinopathy include the disorganization and thinning of the collagen fibers, extensive neovascularization and vascular ingrowth. In addition, spindle-shaped fibroblasts change their shape to a rounded, chondrocyte-like shape. Metabolically, the amount of interfibrillar glycosaminoglycans increases, the synthesis of matrix metalloproteinase enzymes is disregulated and the glutamate production in- 
creases, which finally leads to altered mechanical properties of the tendon [5].

\section{ANIMAL MODELS OF TENDON DISORDERS}

The development of tendon degeneration is a long-term process, at the beginning clinically silent. To understand the processes that occur during tendon degeneration, even in the early stages of tendinopathy, several animal models have been developed. Models of tendon injuries allow the creation of consistent injuries that can be monitored, evaluated at both the cellular and molecular level, and treated under controlled conditions.

The first group of animal tendinopathy models are "active participation models". Tendon deterioration is caused by a mechanical stimulus induced by repetitive treadmill running. This treadmill running overuse animal model of tendinopathy is widely used mainly to evaluate changes in the rotator cuff and supraspinatus tendons [6]. Another model for simulating overuse tendon injuries is repetitive reaching and grasping [7]. Both animal models of overuse tendon injuries result in functional changes as well as inflammatory responses.

The second group consists of "passive participation models". Tendon deterioration is caused without the participation of the animal by using kicking machines to apply passive flexion and extension of the ankle joint of a rabbit under anaesthesia, while simultaneously inducing the contraction of the muscles with an electrical stimulus [8]. This model produces only discrete changes in inflammatory and collagen gene expression and no histopathological changes. Eleven weeks after injury, the changes are proliferative and reparative rather than degenerative in nature. Similar observations have been published by Messner et al. [9]. Recent studies used a repetitive long-term muscle stimulation model alone to study molecular changes in the rabbit flexor digithorum profundus tendon [10]. Long-term stimulation of the muscles led to a tendon injury similar to that seen with the treadmill running model. Another passive model of tendinophaty is dropping a w eight on the exposed Achilles tendon of a rat under anesthesia [11]. Tendinopathy of the rotator cuff is modeled by compression of the thoracoacromial arch using an Achilles tendon allograft transplanted around the acromion [12] or bone plates transplanted onto the surface of the acromion [13]. These models, when combined with a running wheel, produce consistent significant changes in tendon properties $[6,14]$ and confirm the theory of the multifactorial causation of tendinophaty.

A third group are chemically induced models of tendon disorders. Collagenase application to the tendon is the mostly widely used model. These models produce a consistent and reproducible lesion accompanied by an inflammatory reaction. The affected tendons are the flexor dighitorum superficialous tendon, the deep digital flexor tendon, the Achilles tendon, the patellar tendon and the deep digital flexor tendon [15-20]. The amount of collagenase allows for tight control of the altered parameters. Also, a mixture of cytokines [21], carrageenan, a vegetable polysaccharide [22], corticosteroids [23], perfloxacin [24] and prostaglandins [25] have been used to induce a chemical tendon injury.

As the above descriptions make clear, several models of tendon injury have been developed. The main advantage of the active models is their use of repetitive force for developing a tendon injury, which is believed to be the causative mechanism of tendinophaty in humans. The disadvantages of these models are the time consuming process to develop the lesions and a certain inconsistency. Chemically induced models produce more precise lesions and are less time consuming, but the etiology is different than that in humans. More than one model as well as more than one species of animal should be used to evaluate potential treatment of tendinophaty.

\section{MESENCHYMAL STEM CELLS FOR TENDON TRANSPLANTATION}

The discovery of mesenchymal stem cells dates back to the 1960s [26]. Friedenstein and coworkers discovered that bone marrow from the iliac crest, when plated on a plastic dish and after the removal of floating hematopoetic cells, contains a population of fibroblast-like cells, adherent to the plastic, that can differentiate into chondrocytes and osteoblasts. They named these cells mesenchymal stem cells due their ability to differentiate into cells of mesodermal origin [27]. Bone marrow blood consists of two types of stem cells, hematopoetic stem cells and non-hematopoetic mesenchymal stem cells (MSCs). MSCs represent $0.001 \%$ of the total bone marrow. MSCs are isolated from bone marrow using their adherence to plastic or their separation by a Percoll gradient [28]. Another source of MSCs is adipose tissue, which produces MSCs similar to bone marrow MSCs, but easier to produce with broader therapeutic capacity [29]. MSCs have also been found in umbilical cord blood [30], dental tissues [31], synovial fluid [32], palatine tonsil [33], the parathyroid gland [34] and the fallopian tubes [35]. MSC transplantation is a promising strategy because of its relative lack of ethical problems and the absence of any development of teratomas, as observed after embryonic stem cell or iPS cell transplantations; in addition, MSCs are easily harvested using a minimally invasive procedure.

MSCs show heterogeneity in culture. They can have a fibroblast-like shape, a giant fat cell shape, a blanket cell shape or a spindle shape and can appear as flattened cells or as very small round cells [36]. The relation between 
their morphology and shape remains unclear. According to the International Society for Cellular Therapy, three criteria characterize MSCs: 1) plastic adherence; 2) the expression of CD105, CD73 and CD90 and no expression of CD45, CD34, CD14, CD11b, CD79, CD19 or HLA-DR using flow cytometry; 3 ) the capacity to differentiate into osteoblasts, adipocytes and chondroblasts [37]. Several studies have been published showing that MSCs have the ability to differentiate into cells of all three germ layers cardiomyocytes, endothelial smooth muscle cells, neural cells, pancreatic beta cells [38-40], but further examination of the properties of these cells is necessary to confirm their full functionality.

MSCs are immune privileged cells expressing a low level of major histocompactibility complex (MHC) class I antigens and no MHC II molecules. For this reason, MSCs do not activate $\mathrm{T}$ cell immune responses, but they could be attacked by natural killer cells due to their low MHC I expression [41,42]. This immune phenotype allows MSCs from children to persist in their mothers for decades [43].

The multipotent differentiation capacity of MSCs, their unique immunological properties, availability and easy manipulations have attracted researches to mesenchymal stem cell therapies in many medical fields. MSCs also demonstrate the production of trophic factors [44], minor spontaneous differentiation when expanded in vitro [45], and an immunosuppressive effect [46]. These properties predispose MSCs for use in cell replacement, repair and regeneration and immunomodulation in experimental and clinical studies. The list of potential clinical applications is exhaustive, including intervertebral disc repair [47], diabetes mellitus [48], stroke [49], spinal cord injury [50], wound healing and repair [51] etc.

\section{EXPERIMENTAL TREATMENT OF TENDON DISORDERS WITH MSCS}

The use of mesenchymal stem cells as an effective therapy to repair tendon disorders has been investigated over the last two decades. Pacini et al. proved that autologous undifferentiated MSCs implanted into the incompletely damaged tendons of racehorses improves clinical recovery as measured by ultrasonography and the ability to return to racing [52].

Parallel studies have been performed to demonstrate the fate of autologous or allogenic mesenchymal stem cells transplanted into superficial digital flexor tendon injuries in the horse. Post mortem examinations revealed that the MSCs were located mainly within the injected lesions and no visible cell-mediated immune response was observed to allogeneic MSCs in either of the host horses [53].

A series of equine studies comparing expanded cul- tured MSCs and a mononuclear fraction of bone marrow stromal cells with placebo treatment of experimental tendinitis has been published by Crovace et al. [54-56], who reported that treatment with either MSCs or the mononuclear fraction resulted in similar improved healing of the tendon extracellular matrix of in the treated horses.

In another study, Okamoto et al. [57] isolated and cultured bone marrow cells (BMCs) from 9 Fisher rats. They compared the use of BMCs, MSCs, or no cells for the treatment of an Achilles tendon defect. The ultimate failure load in the BMC group was significantly greater than in the MSC and control groups at 7 and 14 days. After 28 days, the ultimate failure load in the BMC group was the same as that of the normal tendon. Histologically, these results correlated with more intense collagen III staining after 7 days and a switch to more intense type I collagen staining after 28 days in the BMC group compared with the MSC group. In addition, the expression of TGF- $\beta$ and vascular endothelial growth factor (VEGF) appeared to be greater in the BMC group at 4 days compared with the MSC and control groups.

Kida et al. found that bone marrow cells have a positive influence on the healing process of a tendon and tracked the fate and effectiveness of bone marrow cells migrating from drilled bone in the close proximity of the rotator cuff [58]. Kryger et al. compared mesenchymal stromal cells derived from bone marrow and from adipose tissue and found that both types of cells had similar properties in vivo and in vitro, but adipopose-derived MSCs could proliferate faster in cell culture [59]. Small animal studies suggest that after transplantation, MSCs display the phenotypic characteristics of the endogenous surrounding tissue and may be an effective treatment for ligament injury [60-62].

Cell therapy with MSCs was more successful than with chondrocytes in native bone-tendon junction repair in a degenerative rat model [63]. In contrast, Gulotta et al. performed a controlled laboratory study using the transplantation of MSCs in a fibrin carrier into the supraspinatus tendon and found no differences in the amount of new cartilage formation or collagen fiber organization as well as no differences in the biomechanical strength of the repairs, the cross-sectional area, the peak stress to failure, or the stiffness despite confirmation of the presence and metabolic activity of the MSCs [64]. Another advantage of MSCs is their easy genetic manipulation. Adenoviral transduced MSCs with membrane type 1 matrix metalloproteinase [65] or with scleraxis [66] improved rotator cuff healing. MSCs in a fibrin glue also enhanced tendon graft osteointegration of the anterior cruciate ligament [67], and when transplanted into a bone tunnel improved the insertion healing of tendon to bone in a rabbit model through the formation of fibrocartilagenous attachment at early time points [68]. 
While the administration of MSCs alone appears to provide benefits for hematopoetic, neuronal and cardiac diseases, tendon repair often requires the structural and mechanical support provided by a scaffold. Collagen, laminin and fibrin are effective supports for MSCs in the initial stages of tendon injury repair [69-72].

Collagen gels were seeded with rabbit bone marrowderived mesenchymal stem cells (MSCs) and contracted onto sutures at initial cell densities of 1, 4, and 8 million cells $/ \mathrm{ml}$. These MSC-collagen composites were then implanted into full thickness, full length, central defects created in the patellar tendons of the animal donors of the cells. These autologous repairs were compared to the natural repair of identical defects on the contralateral side. The results showed that surgical implantation of the tissue engineered MSC-collagen composites significantly improved the biomechanical properties of the tendon repair tissues, although greater MSC concentrations produced no additional significant histological or biomechanical improvement [73].

A variety of different carriers such as type I collagen gels [72], collagen sponges [74] and fibrin [75] have been used in animal models to deliver MSCs to the Achilles, patellar or rotator cuff tendons.

Our recent unpublished results showed that human MSCs when implanted to the rat Achilles tendon injury increase the amount of collagen I and III and neovascularization in the site of injury.

\section{PARMACOLOGY OF MSCS}

In order to utilize MSC treatment in clinical trials, the conditions imposed by the European Medical Agency should be met regarding adequate preclinical supporting data. Although there have already been a number of animal experiments and even clinical trials and case reports with MSCs, only a small number of them can be utilized in the Investigator Brochure as supporting the safety and/ or efficacy of MSC treatment. Three important aspects of the experimental work should be considered to support future clinical trial submission: similarity of methodology (especially the cell harvesting and in vitro expansion procedures), statistical quality (relevant number of subjects and validity of results), and cell characterization (panel of FACS-analysed surface antigens and if the differentiation of the cells was verified).

The acute systemic toxicity of allogeneic MSCs was studied in gamma irradiated rats [76]; there were no significant differences between test animals and controls regarding the presence of respiratory distress upon infusion, clinical assessment, haematology and clinical chemistry analysis after administration of in vitro expanded MSCs. Gross necropsy and histopathological analysis showed no organ profile alterations. There was no significant evidence for allogeneic antibody production or T-cell sensi- tization upon MSC infusion. Although the article does not specify the details of cell characterization, the company description of MultiStem ${ }^{\circledR}$ (multipotent adult progenitor cells) includes plastic adherence, multipotence and positivity for CD105, CD73 and CD90 and negativity for CD45 and CD34.

The biodistribution of MSCs after systemic application is an important aspect to be considered for future clinical use. In order to transfer experimental data to the clinic, relevant tracking models for the cells should be constructed, such models include labelling the cells (immunolabeling, membrane soluble dyes, gene transfer) or utilizing non-autologous cells, such as human cells transplanted into an animal or allogeneic cells from an animal of the opposite sex and staining for the Y chromosome. An example of a MSC biodistribution study was published by Ezquer [77], in which the authors found systemically implanted MSCs in the bone marrow, kidneys and heart. Data on the migration and biodistribution of autologous MSCs in humans have not yet been published; however, the distribution of a similar cell type, bone marrow mononuclear cells (BMMCs), was analysed after intravenous injection [78]. Whole body scintigraphies indicated cell homing to the brain of all patients with a chronic ischemic stroke at $2 \mathrm{~h}$ post-infarct, while the remaining uptake was mainly distributed to the liver (44\%), lungs $(9 \%)$, spleen (4\%), kidneys (4\%) and bladder (9\%). Moreover, quantification of uptake using Single-Photon Emission Computed Tomography (SPECT) at $2 \mathrm{~h}$ post-infarct showed the preferential accumulation of radioactivity in the hemisphere affected by the ischemic infarct in all patients. However, at $24 \mathrm{~h}$ homing could only be distinguished in the brains of 2 patients, while in all patients uptake was still seen in the other organs.

Despite many therapeutic benefits, MSCs have various adverse effects, mainly oncological. It was shown under experimental conditions that MSCs, when injected together with tumor cells, supported the growth of the tumor cells [79]. MSCs have been related to the promotion of metastasis [80] and play a role in the drug resistance of various cancer cells [81]. The immunosuppressive effect of MSCs encourages tumor growth, MSCs migrate to the tumor stroma, and promotes the angiogenesis, migration, invasion and metastasis of tumors [82]. The malignant transformation of MSCs when expanded in vitro has also been reported due to chromosomal instability in long-term culture [83]. Genetic modulation of MSCs can increase their oncogenic potential [84].

\section{CLINICAL STUDIES}

Despite the promising MSC-mediated effects on tendon healing noted in a number of animal studies, only a few clinical stem cell studies have been reported. Orthopae- 
dic stem cell studies in humans have predominantly focused upon enhancing bone healing, particularly in the spine, foot and ankle, and fracture surgery. Centeno et al. treated 227 patients with autologous MSCs that were cultured and then injected into peripheral joints $(n=213)$ or intervertebral discs $(n=13)$ [85]. The patients underwent disease surveillance for an average of 10.6 months, and no malignant transformations were reported. One patient was diagnosed with cancer which the authors believe was "certainly unrelated" to the MSC therapy. Seven patients had complications related to the injection, and 3 possible stem-cell-related complications were reported. Forty-five of the patients had serial MRIs for up to 2 years, and none of the patients showed any evidence of tumor formation, suggesting that MSC therapy is a relatively safe and well-tolerated procedure.

A pilot study enrolled 14 patients with complete rotator cuff tears repaired with transosseous stitches through miniopen incisions. Prior to cuff repair, autologous bone marrow mononuclear cells (BMMCs) were harvested from the iliac crest and subsequently injected into the repaired tendon borders [86]. The BMMC fractions were obtained by cell sorting and resuspended in saline enriched with $10 \%$ autologous serum. These patients were monitored for a minimum of 12 months, and their University of California, Los Angeles scores improved on average from $12 \pm 3.0$ to $31 \pm 3.2$, and tendon integrity was demonstrated by magnetic resonance imaging in all 14 patients. No control group was included in this study, but historically for this procedure, overall rates of rerupture during the first postoperative year range from $25 \%$ to $65 \%$, depending on lesion extent. Unfortunately, only 14 patients were enrolled in this study, making it difficult to determine the efficacy of BMMCs as an adjunct to cuff repair at this time. However, the implantation of BMMCs in RC tendon borders appears to be a safe and promising approach to enhance the efficacy of tendon repair.

Besides MSCs, other cellular therapies have been shown to clinically improve tendon healing. Clarke et al. applied skin-derived tenocyte-like cells to 33 patients with patellar tendinopathy and compared them to 27 patients who were treated with plasma [87]. The group receiving stem cell treatment noted a significant improvement in
Victorian Institute of Sport Assessment (VISA) scores. While both the cell and plasma groups showed an improvement in tendon hypoechogenicity on ultrasound and tear size, only the cell group showed a significant decrease in tendon thickness.

A pilot study of 12 patients with refractory elbow epicondylitis treated with collagen producing cells derived from dermal fibroblasts showed a significant improvement in the patient-rated tennis elbow evaluation scale and ultrasound tendon appearance [88].

Mazzocca et al. used connective tissue progenitor cells (CTP) for rotator cuff repair in 23 patients and 23 controls. In the study, a standardized protocol for utilizing CTP and a potential positive therapeutic effect to enhance the rotator cuff healing process have been presented [89]. Results of the clinical studies are summarized in Table 1.

\section{SUMMARY}

Recent data provide extensive information about utilizing mesenchymal stem cells in regenerative medicine. Regarding tendons, the application of MSCs increase collagen fiber density, enhance tissue architecture and increase biomechanical strength. Due to the mesenchymal origin of these cells, they have been used to facilitate tendon tissue regeneration, but several questions concerning the clinical use of MSCs have been raised. Safety concerns about the use of mesenchymal stem cells in terms of their immunosuppressive effect, their possible genetic transformation and their manufacture for clinical use (expansion, phenotype and genetic stability in culture, cryopreservation and banking, microbial contamination) should be carefully considered [90]. In the face of many promising experimental and preclinical results, additional questions regarding the role of MSCs in the tendon healing process need to be addressed in order to achieve a better understanding of native tendon healing, the signal pathways for inducing tissue regeneration, and the molecular signaling for MSC differentiation. An interdisciplinary approach, including basic research in biology, bioengineering and clinical research, is required to achieve the successful clinical transfer of MSC treatment in tendon regeneration.

Table 1. Clinical studies.

\begin{tabular}{ccc}
\hline & \multicolumn{2}{c}{ Clinical studies } \\
\hline Authors & Treatment & Confirm the safety of the MSCs implantation \\
Centeno et al. 2010 & MSCs & MSCs is safe approach to treat tendon disorders \\
Ellera Gomes et al. 2012 & BMMCs & VISA score was significantly improved \\
Clarke et al. 2011 & Tenocyte-like cells derived from skin & Significant improvement in ultrasound appearance \\
Connell et al. 2009 & Tenocyte-like cells derived from skin & Positive therapeutic effect \\
Mazzocca et al. 2010 & Connective tissue progenitor cells &
\end{tabular}




\section{ACKNOWLEDGEMENTS}

This work was supported by the grant GAČR, P304/10/0326.

\section{REFERENCES}

[1] Astrom, M. and Rausing, A. (1995) Chronic achilles tendinopathy. A survey of surgical and histopathologic findings. Clinical Orthopaedics and Related Research, 151164.

[2] Khan, K.M., Maffulli, N., Coleman, B.D., Cook, J.L. and Taunton, J.E. (1998) Patellar tendinopathy: Some aspects of basic science and clinical management. British Journal of Sports Medicine, 32, 346-355. doi:10.1136/bjsm.32.4.346

[3] Jarvinen, M., Jozsa, L., Kannus, P., Jarvinen, T.L., Kvist, M. and Leadbetter, W. (1997) Histopathological findings in chronic tendon disorders. candinavian Journal of Medicine and Science in Sports, 7, 86-95. doi:10.1111/j.1600-0838.1997.tb00124.x

[4] Backman, L.J., Andersson, G., Wennstig, G., Forsgren, S. and Danielson, P. (2011) Endogenous substance P production in the Achilles tendon increases with loading in an in vivo model of tendinopathy-peptidergic elevation preceding tendinosis-like tissue changes. Journal of $\mathrm{Mu}$ sculoskeletal and Neuronal Interactions, 11, 133-140.

[5] Lake, S.P., Ansorge, H.L. and Soslowsky, L.J. (2008) Animal models of tendinopathy. Disability and Rehabilitation, 30, 1530-1541. doi:10.1080/09638280701785460

[6] Soslowsky, L.J., Thomopoulos, S., Esmail, A., Flanagan, C.L., Iannotti, J.P., Williamson, J.D. and Carpenter, J.E. (2002) Rotator cuff tendinosis in an animal model: Role of extrinsic and overuse factors. Annual Review of Biomedical Engineering, 30, 1057-1063.

[7] Barbe, M.F., Barr, A.E., Gorzelany, I., Amin, M., Gaughan, J.P. and Safadi, F.F. (2003) Chronic repetitive reaching and grasping results in decreased motor performance and widespread tissue responses in a rat model of MSD. Journal of Orthopaedic Research, 21, 167-176. doi:10.1016/S0736-0266(02)00086-4

[8] Archambault, J.M., Hart, D.A. and Herzog, W. (2001) Response of rabbit Achilles tendon to chronic repetitive loading. Connective Tissue Research, 42, 13-23.

[9] Messner, K., Wei, Y., Andersson, B., Gillquist, J. and Rasanen, T. (1999) Rat model of Achilles tendon disorder. A pilot study. Cells Tissues Organs, 165, 30-39. doi: 16671

[10] Nakama, L.H., King, K.B., Abrahamsson, S. and Rempel, D.M. (2005) Evidence of tendon microtears due to cyclical loading in an in vivo tendinopathy model. Journal of Orthopaedic Research, 23, 1199-1205. doi:10.1016/j.orthres.2005.03.006

[11] Lee, E.W., Maffulli, N., Li, C.K. and Chan, K.M. (1997) Pulsed magnetic and electromagnetic fields in experimental achilles tendonitis in the rat: A prospective randomized study. Archives of Physical Medicine and Rehabilitation, 78, 399-404.

[12] Soslowsky, L.J., Carpenter, J.E., DeBano, C.M., Banerji,
I. and Moalli, M.R. (1996) Development and use of an animal model for investigations on rotator cuff disease. Journal of Shoulder and Elbow Surgery, 5, 383-392. doi:10.1114/1.1509765

[13] Schneeberger, A.G., Nyffeler, R.W. and Gerber, C. (1998) Structural changes of the rotator cuff caused by experimental subacromial impingement in the rat. Journal of Shoulder and Elbow Surgery, 7, 375-380.

[14] Carpenter, J.E., Flanagan, C.L., Thomopoulos, S., Yian, E.H. and Soslowsky, L.J. (1998) The effects of overuse combined with intrinsic or extrinsic alterations in an animal model of rotator cuff tendinosis. The American Journal of Sports Medicine, 26, 801-807.

[15] Keg, P.R., van den Belt, A.J., Merkens, H.W., Barneveld, A. and Dik, K.J. (1992) The effect of regional nerve blocks on the lameness caused by collagenase induced tendonitis in the midmetacarpal region of the horse: A study using gait analysis, and ultrasonography to determine tendon healing. Zentralbl Veterinarmed A, 39, 349-364.

[16] Silver, I.A., Brown, P.N., Goodship, A.E., Lanyon, L.E., McCullagh, K.G., Perry, G.C. and Williams, I.F. (1983) A clinical and experimental study of tendon injury, healing and treatment in the horse. Equine Veterinary Journal, $1-43$.

[17] Williams, I.F., McCullagh, K.G., Goodship, A.E. and Silver, I.A. (1984) Studies on the pathogenesis of equine tendonitis following collagenase injury. Research in Veterinary Science, 36, 326-338.

[18] Dahlgren, L.A., Mohammed, H.O. and Nixon, A.J. (2005) Temporal expression of growth factors and matrix molecules in healing tendon lesions. Journal of Orthopaedic Research, 23, 84-92. doi:10.1016/j.orthres.2004.05.007

[19] Dahlgren, L.A., van der Meulen, M.C., Bertram, J.E., Starrak, G.S. and Nixon, A.J. (2002) Insulin-like growth factor-I improves cellular and molecular aspects of healing in a collagenase-induced model of flexor tendinitis. Journal of Orthopaedic Research, 20, 910-919. doi:10.1016/S0736-0266(02)00009-8

[20] Kersh, K.D., McClure, S.R., Van Sickle, D. and Evans, R.B. (2006) The evaluation of extracorporeal shock wave therapy on collagenase induced superficial digital flexor tendonitis. Veterinary and Comparative Orthopaedics and Traumatology, 19, 99-105.

[21] Stone, D., Green, C., Rao, U., Aizawa, H., Yamaji, T., Niyibizi, C., Carlin, G. and Woo, S.L. (1999) Cytokineinduced tendinitis: a preliminary study in rabbits. Journal of Orthopaedic Research, 17, 168-177. doi:10.1002/jor.1100170204

[22] Marsolais, D., Duchesne, E., Cote, C.H. and Frenette, J. (2007) Inflammatory cells do not decrease the ultimate tensile strength of intact tendons in vivo and in vitro: Protective role of mechanical loading. Journal of Applied Physiology, 102, 11-17. doi:10.1152/japplphysiol.00162.2006

[23] Tatari, H., Kosay, C., Baran, O., Ozcan, O. and Ozer, E. (2001) Deleterious effects of local corticosteroid injections on the Achilles tendon of rats. Archives of Orthopaedic and Trauma Surgery, 121, 333-337. 
[24] Kato, M., Takada, S., Kashida, Y. and Nomura, M. (1995) Histological examination on Achilles tendon lesions induced by quinolone antibacterial agents in juvenile rats. Toxicologic Pathology, 23, 385-392.

[25] Sullo, A., Maffulli, N., Capasso, G. and Testa, V. (2001) The effects of prolonged peritendinous administration of PGE1 to the rat Achilles tendon: A possible animal model of chronic Achilles tendinopathy. Journal of Orthopaedic Science, 6, 349-357. doi:10.1007/s0077610060349

[26] Friedenstein, A.J., Piatetzky, S. and Petrakova, K.V. (1966) Osteogenesis in transplants of bone marrow cells. Journal of Embryology \& Experimental Morphology, 16, 381390.

[27] Caplan, A.I. (1991) Mesenchymal stem cells. Journal of Orthopaedic Research, 9, 641-650. doi:10.1002/jor.1100090504

[28] Barry, F.P. and Murphy, J.M. (2004) Mesenchymal stem cells: Clinical applications and biological characterization. Journal of Embryology \& Experimental Morphology, 36, 568-584. doi:10.1016/j.biocel.2003.11.001

[29] Gimble, J.M., Katz, A.J. and Bunnell, B.A. (2007) Adipose-derived stem cells for regenerative medicine. Circulation Research, 100, 1249-1260. doi:10.1161/01.RES.0000265074.83288.09

[30] Lee, O.K., Kuo, T.K., Chen, W.M., Lee, K.D., Hsieh, S.L. and Chen, T.H. (2004) Isolation of multipotent mesenchymal stem cells from umbilical cord blood. Blood, 103, 1669-1675. doi:10.1182/blood-2003-05-1670

[31] Huang, G.T., Gronthos, S. and Shi, S. (2009) Mesenchymal stem cells derived from dental tissues vs. those from other sources: Their biology and role in regenerative medicine. Journal of Dental Research, 88, 792-806. doi:10.1177/0022034509340867

[32] Jones, E.A., English, A., Henshaw, K., Kinsey, S.E., Markham, A.F., Emery, P. and McGonagle, D. (2004) Enumeration and phenotypic characterization of synovial fluid multipotential mesenchymal progenitor cells in inflammatory and degenerative arthritis. Arthritis Rheum, 50, 817-827. doi:10.1002/art.20203

[33] Janjanin, S., Djouad, F., Shanti, R.M., Baksh, D., Gollapudi, K., Prgomet, D., Rackwitz, L., Joshi, A.S. and Tuan, R.S. (2008) Human palatine tonsil: A new potential tissue source of multipotent mesenchymal progenitor cells. Arthritis Research \& Therapy, 10, R83. doi:10.1186/ar2459

[34] Shih, Y.R., Kuo, T.K., Yang, A.H., Lee, O.K. and Lee, C.H. (2009) Isolation and characterization of stem cells from the human parathyroid gland. Cell Proliferation, 42, 461-470. doi:10.1111/j.1365-2184.2009.00614.x

[35] Jazedje, T., Perin, P.M., Czeresnia, C.E., Maluf, M., Halpern, S., Secco, M., Bueno, D.F., Vieira, N.M., Zucconi, E. and Zatz, M. (2009) Human fallopian tube: A new source of multipotent adult mesenchymal stem cells discarded in surgical procedures. Journal of Translational Medicine, 7, 46. doi:10.1186/1479-5876-7-46

[36] Pevsner-Fischer, M., Levin, S. and Zipori, D. (2011) The origins of mesenchymal stromal cell heterogeneity. Stem Cell Reviews, 7, 560-568. doi:10.1007/s12015-011-9229-7
[37] Dominici, M., Le Blanc, K., Mueller, I., Slaper-Cortenbach, I., Marini, F., Krause, D., Deans, R., Keating, A., Prockop, D. and Horwitz, E. (2006) Minimal criteria for defining multipotent mesenchymal stromal cells. The international society for cellular therapy position statement. Cytotherapy, 8, 315-317. doi:10.1080/14653240600855905

[38] Jiang, Y., Jahagirdar, B.N., Reinhardt, R.L., Schwartz, R.E., Keene, C.D., Ortiz-Gonzalez, X.R., Reyes, M., Lenvik, T., Lund, T., Blackstad, M., Du, J., Aldrich, S., Lisberg, A., Low, W.C., Largaespada, D.A. and Verfaillie, C.M. (2002) Pluripotency of mesenchymal stem cells derived from adult marrow. Nature, 418, 41-49. doi: $10.1038 /$ nature 00870

[39] Gao, F., Wu, D.Q., Hu, Y.H. and Jin, G.X. (2008) Extracellular matrix gel is necessary for in vitro cultivation of insulin producing cells from human umbilical cord blood derived mesenchymal stem cells. Chinese Medical Journal (English Edition), 121, 811-818.

[40] Sun, Y., Chen, L., Hou, X.G., Hou, W.K., Dong, J.J., Sun, L., Tang, K.X., Wang, B., Song, J., Li, H. and Wang, K.X. (2007) Differentiation of bone marrow-derived mesenchymal stem cells from diabetic patients into insulin-producing cells in vitro. Chinese Medical Journal (English Edition), 120, 771-776.

[41] Javazon, E.H., Beggs, K.J. and Flake, A.W. (2004) Mesenchymal stem cells: Paradoxes of passaging. Experimental Hematology, 32, 414-425. doi:10.1016/j.exphem.2004.02.004

[42] Moretta, A., Bottino, C., Vitale, M., Pende, D., Cantoni, C., Mingari, M.C., Biassoni, R. and Moretta, L. (2001) Activating receptors and coreceptors involved in human natural killer cell-mediated cytolysis. Annual Review of Immunology, 19, 197-223. doi:10.1146/annurev.immunol.19.1.197

[43] O’Donoghue, K., Chan, J., De la Fuente, J., Kennea, N., Sandison, A., Anderson, J.R., Roberts, I.A. and Fisk, N.M. (2004) Microchimerism in female bone marrow and bone decades after fetal mesenchymal stem-cell trafficking in pregnancy. Lancet, 364, 179-182. doi:10.1016/S0140-6736(04)16631-2

[44] Caplan, A.I. and Dennis, J.E. (2006) Mesenchymal stem cells as trophic mediators. Journal of Cellular Biochemistry, 98, 1076-1084. doi:10.1002/jcb.20886

[45] Pittenger, M.F., Mackay, A.M., Beck, S.C., Jaiswal, R.K., Douglas, R., Mosca, J.D., Moorman, M.A., Simonetti, D.W., Craig, S. and Marshak, D.R. (1999) Multilineage potential of adult human mesenchymal stem cells. Science, 284, 143-147. doi:10.1126/science.284.5411.143

[46] Le Blanc, K and Ringden, O. (2005) Immunobiology of human mesenchymal stem cells and future use in hematopoietic stem cell transplantation. Biology of Blood and Marrow Transplantation, 11, 321-334. doi:10.1016/j.bbmt.2005.01.005

[47] Acosta Jr., F.L., Metz, L., Adkisson, H.D., Liu, J., Carruthers-Liebenberg, E., Milliman, C., Maloney, M. and Lotz, J.C. (2011) Porcine intervertebral disc repair using allogeneic juvenile articular chondrocytes or mesenchymal stem cells. Tissue Engineering Part A, 17, 3045-3055. 
doi:10.1089/ten.tea.2011.0229

[48] Yeung, T.Y., Seeberger, K.L., Kin, T., Adesida, A., Jomha, N., Shapiro, A.M. and Korbutt, G.S. (2012) Human mesenchymal stem cells protect human islets from pro-inflammatory cytokines. PLOS ONE, 7, e38189. doi:10.1371/journal.pone.0038189

[49] Guo, F., Lv, S., Lou, Y., Tu, W., Liao, W., Wang, Y. and Deng, Z. (2012) Bone marrow stromal cells enhance the angiogenesis in ischaemic cortex after stroke: Involvement of notch signalling. Cell Biology International, 36, 997-1004. doi:10.1042/CBI20110596

[50] Urdzikova, L., Jendelova, P., Glogarova, K., Burian, M., Hajek, M. and Sykova, E. (2006) Transplantation of bone marrow stem cells as well as mobilization by granulocyte-colony stimulating factor promotes recovery after spinal cord injury in rats. Journal of Neurotrauma, 23, 1379-1391. doi:10.1089/neu.2006.23.1379

[51] Xie, M.W., Gorodetsky, R., Micevicz, E.D., Mackenzie, N.C., Gaberman, E., Levdansky, L. and McBride, W.H. (2013) Marrow-derived stromal cell delivery on fibrin microbeads can correct radiation-induced wound-healing deficits. Journal of Investigative Dermatology, 133, 553561

[52] Pacini, S., Spinabella, S., Trombi, L., Fazzi, R., Galimberti, S., Dini, F., Carlucci, F. and Petrini, M. (2007) Suspension of bone marrow-derived undifferentiated mesenchymal stromal cells for repair of superficial digital flexor tendon in race horses. Tissue Engineering, 13, 29492955. doi:10.1089/ten.2007.0108

[53] Guest, D.J., Smith, M.R. and Allen, W.R. (2008) Monitoring the fate of autologous and allogeneic mesenchymal progenitor cells injected into the superficial digital flexor tendon of horses: Preliminary study. Equine Veterinary Journal, 40, 178-181. doi:10.2746/042516408X276942

[54] Crovace, A., Lacitignola, L., De Siena, R., Rossi, G. and Francioso, E. (2007) Cell therapy for tendon repair in horses: An experimental study. Veterinary Research Communications, 31, 281-283. doi:10.1007/s11259-007-0047-y

[55] Crovace, A., Lacitignola, L., Rossi, G. and Francioso, E. (2010) Histological and immunohistochemical evaluation of autologous cultured bone marrow mesenchymal stem cells and bone marrow mononucleated cells in collagenase-induced tendinitis of equine superficial digital flexor tendon. Veterinary Medicine International, 2010, 250978.

[56] Lacitignola, L., Crovace, A, Rossi G., and Francioso, E. (2008) Cell therapy for tendinitis, experimental and clinical report. Veterinary Research Communications, 32, S33-S38. doi:10.1007/s11259-008-9085-3

[57] Okamoto, N., Kushida, T., Oe, K., Umeda, M., Ikehara, S. and Iida, H. (2010) Treating Achilles tendon rupture in rats with bone-marrow-cell transplantation therapy. The Journal of Bone \& Joint Surgery, 92, 2776-2784. doi:10.2106/JBJS.I.01325

[58] Kida, Y., Morihara, T., Matsuda, K.I., Kajikawa, Y., Tachiiri, H., Iwata, Y., Sawamura, K., Yoshida, A., Oshima, Y., Ikeda, T., Fujiwara, H., Kawata, M. and Kubo, T. (2013) Bone marrow-derived cells from the footprint in- filtrate into the repaired rotator cuff. Journal of Shoulder and Elbow Surgery, 22, 197-205.

[59] Kryger, G.S., Chong, A.K., Costa, M., Pham, H., Bates, S.J. and Chang, J. (2007) A comparison of tenocytes and mesenchymal stem cells for use in flexor tendon tissue engineering. Journal of Hand Surgery, 32, 597-605. doi:10.1016/j.jhsa.2007.02.018

[60] Watanabe, N., Woo, S.L., Papageorgiou, C., Celechovsky, C. and Takai, S. (2002) Fate of donor bone marrow cells in medial collateral ligament after simulated autologous transplantation. Microscopy Research and Technique, 58, 39-44. doi:10.1002/jemt.10115

[61] Li, F, Jia, H. and Yu, C. (2007) ACL reconstruction in a rabbit model using irradiated Achilles allograft seeded with mesenchymal stem cells or PDGF-B gene-transfected mesenchymal stem cells. Knee Surgery, Sports Traumatology, Arthroscopy, 15, 1219-1227. doi:10.1007/s00167-007-0385-X

[62] Soon, M.Y., Hassan, A., Hui, J.H., Goh, J.C. and Lee, E.H. (2007) An analysis of soft tissue allograft anterior cruciate ligament reconstruction in a rabbit model: A short-term study of the use of mesenchymal stem cells to enhance tendon osteointegration. The American Journal of Sports Medicine, 35, 962-971. doi:10.1177/0363546507300057

[63] Nourissat, G., Diop, A., Maurel, N., Salvat, C., Dumont, S., Pigenet, A., Gosset, M., Houard, X. and Berenbaum, F. (2010) Mesenchymal stem cell therapy regenerates the native bone-tendon junction after surgical repair in a degenerative rat model. PLOS ONE, 5, e12248. doi:10.1371/journal.pone.0012248

[64] Gulotta, L.V., Kovacevic, D., Ehteshami, J.R., Dagher, E., Packer, J.D. and Rodeo, S.A. (2009) Application of bone marrow-derived mesenchymal stem cells in a rotator cuff repair model. The American Journal of Sports Medicine, 37, 2126-2133. doi:10.1177/0363546509339582

[65] Gulotta, L.V., Kovacevic, D., Montgomery, S., Ehteshami, J.R., Packer, J.D. and Rodeo, S.A. (2010) Stem cells genetically modified with the developmental gene MT1MMP improve regeneration of the supraspinatus tendonto-bone insertion site. The American Journal of Sports Medicine, 38, 1429-1437. doi: $10.1177 / 0363546510361235$

[66] Gulotta, L.V., Kovacevic, D., Packer, J.D., Deng, X.H. and Rodeo, S.A. (2011) Bone marrow-derived mesenchymal stem cells transduced with scleraxis improve rotator cuff healing in a rat model. The American Journal of Sports Medicine, 39, 1282-1289. doi: $10.1177 / 0363546510395485$

[67] Lim, J.K., Hui, J., Li, L., Thambyah, A., Goh, J. and Lee, E.H. (2004) Enhancement of tendon graft osteointegration using mesenchymal stem cells in a rabbit model of anterior cruciate ligament reconstruction. Arthroscopy, 20, 899-910.

[68] Ouyang, H.W., Goh, J.C. and Lee, E.H. (2004) Use of bone marrow stromal cells for tendon graft-to-bone healing: Histological and immunohistochemical studies in a rabbit model. The American Journal of Sports Medicine, 32, 321-327. doi:10.1177/0095399703258682 
[69] Hairfield-Stein, M., England, C., Paek, H.J., Gilbraith, K.B., Dennis, R., Boland, E. and Kosnik, P. (2007) Development of self-assembled, tissue-engineered ligament from bone marrow stromal cells. Tissue Engineering, 13, 703-710. doi:10.1089/ten.2006.0203

[70] Chong, A.K., Ang, A.D., Goh, J.C., Hui, J.H., Lim, A.Y., Lee, E.H. and Lim, B.H. (2007) Bone marrow-derived mesenchymal stem cells influence early tendon-healing in a rabbit achilles tendon model. The Journal of Bone \& Joint Surgery, 89, 74-81. doi:10.2106/JBJS.E.01396

[71] Ouyang, H.W., Cao, T., Zou, X.H., Heng, B.C., Wang, L.L., Song, X.H. and Huang, H.F. (2006) Mesenchymal stem cell sheets revitalize nonviable dense grafts: Implications for repair of large-bone and tendon defects. Transplantation, 82, 170-174. doi:10.1097/01.tp.0000226232.79106.72

[72] Young, R.G., Butler, D.L., Weber, W., Caplan, A.I., Gordon, S.L. and Fink, D.J. (1998) Use of mesenchymal stem cells in a collagen matrix for Achilles tendon repair. Journal of Orthopaedic Research, 16, 406-413. doi:10.1002/jor.1100160403

[73] Awad, H.A., Boivin, G.P., Dressler, M.R., Smith, F.N., Young, R.G. and Butler, D.L. (2003) Repair of patellar tendon injuries using a cell-collagen composite. Journal of Orthopaedic Research, 21, 420-431. doi:10.1016/S0736-0266(02)00163-8

[74] Juncosa-Melvin, N., Boivin, G.P., Gooch, C., Galloway, M.T., West, J.R., Dunn, M.G. and Butler, D.L. (2006) The effect of autologous mesenchymal stem cells on the biomechanics and histology of gel-collagen sponge constructs used for rabbit patellar tendon repair. Tissue Engineering, 12, 369-379. doi:10.1089/ten.2006.12.369

[75] Hankemeier, S., Hurschler, C., Zeichen, J., Van Griensven, M., Miller, B., Meller, R., Ezechieli, M., Krettek, C. and Jagodzinski, M. (2009) Bone marrow stromal cells in a liquid fibrin matrix improve the healing process of patellar tendon window defects. Tissue Engineering Part A, 15, 1019-1030. doi:10.1089/ten.tea.2008.0046

[76] Kovacsovics-Bankowski, M., Mauch, K., Raber, A., Streeter, P.R., Deans, R.J., Maziarz, R.T. and Van't Hof, W. (2008) Pre-clinical safety testing supporting clinical use of allogeneic multipotent adult progenitor cells. Cytotherapy, 10, 730-742. doi:10.1080/14653240802320245

[77] Ezquer, F., Ezquer, M., Simon, V., Pardo, F., Yanez, A., Carpio, D. and Conget, P. (2009) Endovenous administration of bone-marrow-derived multipotent mesenchymal stromal cells prevents renal failure in diabetic mice. Biology of Blood and Marrow Transplantation, 15, 13541365. doi:10.1016/j.bbmt.2009.07.022

[78] Barbosa da Fonseca, L.M., Gutfilen, B., Rosado de Castro, P.H., Battistella, V., Goldenberg, R.C., KasaiBrunswick, T., Chagas, C.L., Wajnberg, E., Maiolino, A., Salles Xavier, S., Andre, C., Mendez-Otero, R. and De Freitas, G.R. (2010) Migration and homing of bone-marrow mononuclear cells in chronic ischemic stroke after intra-arterial injection. Experimental Neurology, 221, 122-128. doi:10.1016/j.expneurol.2009.10.010

[79] Ramasamy, R., Lam, E.W., Soeiro, I., Tisato, V., Bonnet, D. and Dazzi, F. (2007) Mesenchymal stem cells inhibit proliferation and apoptosis of tumor cells: Impact on in vivo tumor growth. Leukemia, 21, 304-310. doi:10.1038/sj.leu.2404489

[80] Lazennec, G. and Jorgensen, C. (2008) Concise review: Adult multipotent stromal cells and cancer: Risk or benefit? Stem Cells, 26, 1387-1394.

doi:10.1634/stemcells.2007-1006

[81] Kurtova, A.V., Balakrishnan, K., Chen, R., Ding, W., Schnabl, S., Quiroga, M.P., Sivina, M., Wierda, W.G., Estrov, Z., Keating, M.J., Shehata, M., Jager, U., Gandhi, V., Kay, N.E., Plunkett, W. and Burger, J.A. (2009) Diverse marrow stromal cells protect CLL cells from spontaneous and drug-induced apoptosis: Development of a reliable and reproducible system to assess stromal cell adhesion-mediated drug resistance. Blood, 114, 44414450. doi:10.1182/blood-2009-07-233718

[82] Shinagawa, K., Kitadai, Y., Tanaka, M., Sumida, T., Kodama, M., Higashi, Y., Tanaka, S., Yasui, W. and Chayama, K. (2010) Mesenchymal stem cells enhance growth and metastasis of colon cancer. International Journal of Cancer, 127, 2323-2333. doi:10.1002/ijc.25440

[83] Takeuchi, M., Takeuchi, K., Kohara, A., Satoh, M., Shioda, S., Ozawa, Y., Ohtani, A., Morita, K., Hirano, T., Terai, M., Umezawa, A. and Mizusawa, H. (2007) Chromosomal instability in human mesenchymal stem cells immortalized with human papilloma virus E6, E7, and hTERT genes. In Vitro Cellular \& Developmental Biology-Animal, 43, 129-138. doi:10.1007/s11626-007-9021-9

[84] Miura, Y., Gao, Z., Miura, M., Seo, B.M., Sonoyama, W., Chen, W., Gronthos, S., Zhang, L. and Shi, S. (2006) Mesenchymal stem cell-organized bone marrow elements: An alternative hematopoietic progenitor resource. Stem Cells, 24, 2428-2436. doi:10.1634/stemcells.2006-0089.

[85] Centeno, C.J., Schultz, J.R., Cheever, M., Robinson, B., Freeman, M. and Marasco, W. (2010) Safety and complications reporting on the re-implantation of culture-expanded mesenchymal stem cells using autologous platelet lysate technique. Current Stem Cell Research \& Therapy, 5, 81-93. doi:10.2174/157488810790442796

[86] Ellera Gomes, J.L., Da Silva, R.C., Silla, L.M., Abreu, M.R. and Pellanda, R. (2012) Conventional rotator cuff repair complemented by the aid of mononuclear autologous stem cells. Knee Surgery, Sports Traumatology, Arthroscopy, 20, 373-377. doi:10.1007/s00167-011-1607-9

[87] Clarke, A.W., Alyas, F., Morris, T., Robertson, C.J., Bell, J. and Connell, D.A. (2011) Skin-derived tenocyte-like cells for the treatment of patellar tendinopathy. The American Journal of Sports Medicine, 39, 614-623. doi:10.1177/0363546510387095

[88] Connell, D., Datir, A., Alyas, F. and Curtis, M. (2009) Treatment of lateral epicondylitis using skin-derived tenocyte-like cells. British Journal of Sports Medicine, 43, 293-298. doi:10.1136/bjsm.2008.056457

[89] Mazzocca, A.D, McCarthy, M.B., Chowaniec, D.M., Cote, M.P., Arciero, R.A. and Drissi, H. (2010) Rapid isolation of human stem cells (connective tissue progenitor cells) from the proximal humerus during arthroscopic rotator cuff surgery. The American Journal of Sports Me- 
dicine, 38, 1438-1447. doi:10.1177/0363546509360924

[90] Wang, Y., Han, Z.B., Song, Y.P. and Han, Z.C. (2012)
Safety of mesenchymal stem cells for clinical application. Stem Cells International, 2012, 652034. 